\title{
Shakespeare: Barroquismo en el arte dramático
}

\author{
por \\ Augrusto Tamayo Vargas
}

La bibliografia dramática de Shakespeare se inicia con un drama
en torno de Enrique VI publicado en 1594, bajo el título de "Pri-
mera Parte de la Contienda de las famosas Casas de York y Lancaster", que es, en verdad, una segunda versión de otro drama anterior del mismo Shakespeare escrito alrededor de 1592. Aún produciría un tercero sobre el mismo tema. Todos ellos nos muestran el interés histórico del autor, al insistir en personajes de la enconada lucha de dos familias: la de York y la de Lancaster, por el trono inglés, que se conoce con el nombre de Guerra de las Dos Rosas. Evidentemente Shakespeare se valió de Crónicas de los Reyes de Inglaterraly, aD iguala que el Ctomanticismo, se dejó arrastrar por un fondo histórico yepor una presentación de caracteres fuertes que llegan a la sensibilidad del espectador por las dos vías: la del sentimiento nacional y la de la impresión temperamental. Además de esas obras primigenias, Shakespeare escribirá Ricardo III, impresa en 1597 y una de sus más importantes tragedias; un Ricardo II; y más tarde su no menos famosa obra Enrique V, asi como su Eduardo III, todas a base del historiador Rafael Holinshed y alrededor de la misma época espectacular y sangrienta en la Historia de Inglaterra. Vendrán en su edad madura a ser objeto de predilección temas mucho más cercanos como Enrique VIII, o Tomás Moore, conservado en manuscrito hasta 1911, en que lo reprodujo facsimilarmente Greg. Y está en la cima de esa producción dramática su Macbeth donde une la historia, la leyenda y la tradición popular inglesas, escrito alrededor de 1606 y solamente impreso en la famosa colección de los dramas de Shakespeare. conocida co. 
mo el Folio de 1623, publicado después de su muerte. El folklore, asimismo, inglés, hablará en Las Alegres Comadres de Windsor.

En realidad, la bibliografia shakesperiana debe remontarse a un poema, publicado desde el primer momento bajo su nombre: Venus y Adonis, de 1593. Seguirá escribiendo poesía: La Violación de Lucrecia, de 1594. Para en el campo poético pasar a la presentación de sus Sonetos, de tanta importancia biográfica, en 1606. Claro que es el folio cle 1623 el que ha de ofrecer la rica gama de 36 obras para teatro, de la niejs variada iemática y carácter dramático. Alli, aquel conjunto nacional anglo-sajón que hemos visto anteriormente. $Y$ también la fuerte tradición galesa que se muestra espléndida en el Rey Lear. Estará presente, asimismo, la veta de la antigüedad clásica, que se patentiza en Shakespeare no sollo por "sus ligeros conocimientos de latín y griego", a qije se refería su amigo Ben Johnson, sino a través de versiones francesas e inglesas de la literatura greco-latina; veta que arranca con un Tito Andrónico y que tiene su más alto representante en el Julio César, escrito a base de Plutarco, como el Antonio y Cleopatra y el Coriolano; pero también están el Pericles, el Troilo y Crésida, etc. Otra expresión clásica notable será La Comedia de las Equivocaciones, basada en Plauto.

El campo de obras dramáticas extraídas del munclo itálico es uno de los más importantés. Se abre con La Fierecilla Domada, que le viene de una comedia de Ariosto; aunque los lejanos antecedentes estén en España y particularmente en el Príncipe Juan Manuel. Adquiere su más renombrada expresión en Romeo y Julieta, que viene de Matteo Bandello, aunque parece que Shakespeare lo recogió por la vía de William Painter y Arthur Brooke. También de Bandello recogería una "novela" para escribir Mucho ruido para nada, y alguna otra para Noche de Reyes. Debe precisarse que Bandello, a su vez, hace presente temas antiguos de larga y recomendada tradición popular europea, que arranca las más veces de la vieja Grecia o de la intermedia Roma. El Sueño de una Noche de Verano es una muestra de conjunción de esas viejas tradiciones que se agolpan ante la imaginación creadora de Shakespeare para una fiesta nupcial; y que forma una obra que oscila entre diversos géneros teatrales para mostrarnos en toda su grandeza la rica sensibilidad artística del autor. Pero aún tenemos para poner en el 
terreno de las influencias italianas El Mercader de Venecia, que juntamente con la anterior se publicaría en 1600, y que deviene, como ha señalado Pedro Henriquez Ureña - a quien tanto se debe, en el mundo de habla hispánica, en la exploración de Shakespearea un cuento de Giovani de Firenze: III Pecorone, como Gimbelino, procede de un cuento de Bocaccio, que es también antecedente lejano de Los dos nobles parientes. Otelo, asimismo, está en la literatura italiana renacentista. Su principal versión en Giraldi Cinthio.

Podría hablarse de un impacto español, aunque Shakespeare no conocía el castellano y sí el italiano. Ese impacto se aprecia en la citada Fierecilla Domada que responde a la historia "de lo que aconteció a un mancebo que casó con una muger muy fuerte et muy brava". Los Dos Hidalgos de Verona que procede de la segunda parte de la Diana del pastoril Jorge de Montemayor. El mismo Romeo y Julieta, que tiene su paralelo en Los Amantes de Teruel, y cuyo argumento principal recoge Lope, por los mismos años de Shakespeare para Castelvines y Monteses, tendría asi parentescos españoles. El Cuenio de Invierno, recreación de novelas de caballería, nos habla de Florisel de Niques de Feliciano de Silva. El Cardenio está indudablemente escrito bajo la inspiración del Quijote de Cervantes. $Y$ aún La Tempesiad puede proceder de un cuento de Noches de Invierno de Antonio de Eslava Pero esta obra, La Tempestad, nos lleva a otra conjunción de elementos diversos que encontramos desde las viejas sagaslabrdicas hasta ef francés Montaigne. América se halla presente en esa obra, con divinidades patagónicas y con Calibán, presumiblemente derivado de "canibal", que a su vez procede de "caribe", aunque también se ha supuesto la ascendencia gitana de "cauliban", que significa negrura, también en opinión de Pedro Henríquez Ureña. De todos modos La Tempestad se relaciona con América a través de Ariel de Rodó, que significó una tendencia idealista hispanoamericana a comienzos de este siglo, que tuvo su mayor repercusión peruana en el pensamiento politico y social de Francisco García Calderón.

Borboteando por fuentes nórdicas, que a su vez salieron de la inmensa torrentera griega, viene hacia Shakespeare la figura de Hamlet. Gilbert Murray hizo un estudio documentado de este per. sonaje danés relacionado con el griego Orestes. Ya se sabe cómo sirvió 
de tema este personaje a los tres más grandes trágicos de la antigüedad helénica: Esquilo, Sófccles y Euripides. Y cómo sintetiza, al lado del sentimiento religioso, la extraña venganza de un hijo que ceba la pasión desatada por el asesinato del padre, en la propia madre $y$ en el amante de ésta. A ese tema clásico se uniercn los pcemas y leyendas nórdicas - Saxo el Loco, Edda, Ambales- con el gris fáustico, que diría Spengler, para llegar al brumcso personaje Hamleí, de Shakespeare, que es la personificación mayor del barroquismo, del romanticismo -pedria decirse asi-ciel siglo XVII. A través de tres versiones diferentes, Shakespeare fue moldeando su personaje definitivo, para ofrecernos el rico tema que mús ha conmovido centro de sus tragedias. El primer texto apareció en 1603, bajo el nombre de Shakespeare y se titulaba: La Trágica Historia de Hamlet, Prir.cipe de Dinamarca; la segunda apareció en 1604 y la tercera Está en el Folio de 1623. Es ésta la definitiva. Y alli se muestra en su integridad el personaje fundamental de Shakespearc, el más intenso. Fundamental predecesor del romanticismo, Shakespeare culmina su obra poética con El Peregrino Apasionado, indudable antecedente del romanticismo inglés del $X \mid X ;$ y su obra dramática con Macbeth y Hamlet, piezas por excelencia para los románticos de todos los tiempos.

Sombreada por los olmos trascurre la vida de Straford a la vera del río Avon. Cuatrocientos años atrás, en el mes de abril de 1564, náció en una casa de esa villa William Shakespeare, a quien habría de llamarse "el alma de mil cimas". Su padre - John Shakespearellegaría alguna vez a ser Alcalde de la población, fundada en el siglo XII. Su madre -Mary Arden- pertenecía a una familia católica que había sufrido persecuciones de la oficial Iglesia Anglicana. De arnbiente provinciano, William Shakespeare llegó a ser actor y autor prominente en los meclios londinenses, donde triunfa por su figura, por el ingenio, por el talento y por amistosa camaradería. Entre 1592 y 1610 realiza una de las más proficuas y más trascendentales obras de la literatura universal en la capital inglesa. En el retiro de Straford -a donde volvió cuando no había cumplido los 50 años -aún escribió su Enrique VIII y su Cardenio; y murió en el mismo lar nativo el 23 de abril de 1616. Oficialmente para Inglaterra el mismo día que desaparecian Cervantes y Garcilaso de la Vega, el Inca. Menguada la fecha para cubrir tres grandes sombras. Más ya 
se sabe que el 23 de abril del calendario inglés estaba atrasado en diez días con relación al continental europeo hasta el siglo XVIII; y así Shakespeare murió sólo el 3 de mayo, superviviendo, por ese lapso, al genio de España y al insigne mestizo de Los Comentarios Reales de los Incas. Hay referencia a su tumba en "The antiquites of Warwrckshire", de 1656.

"Entre mil poetas que fijaron su mirada en la vida misma, uno solo llegó a ser Shakespeare", expresó un autor inglés. Y es que la obra de aquél estuvo destinada a fijar caracteres de personajes vividos. No es la trama, no es la consecuencia moral, no es el tipo ideal o caricaturesco, lo que Shakespeare ofrece mayormente: sino las mil anfructuosidades del alma del hombre. Por ello escapa continuamente del Renacimiento y entra de lleno a lo que se entiende por literatura barroca. Alli bebe el vino fuerte de la condición de los hombres en el claro-oscuro de los bodegones. Expresó las pasiones humanas: abnegaciones y venganzas; sentimientos generosos, ridiculos o viles. Por un lado: la angustia dubitativa de Hamlet. Por otra: la crueldad de Ricaráo III. Más allá: la ambición de Lady Macbeth y el oscuro camino de sangre del esposo atormentado por un profundo sentimiento de culpa. Se rompe en la mayoría de los casos el equilibrio clásico, aunque Shakespeare continúe tradiciones que vienen de Esquilo, en su-impregnación del Destino; de Ovidio, en la elegancia de su dicción, en el juego artístico de los conceptos que no sólo cultiva en et Teatro sino en sus Sonetos; de los cuentistas italianos y lespanoles delnenacimiento; de los clásicos ingleses que le anteceden. Pero donde en Marlowe está la inquietud y la turbulencia, en Shakespeare aumenta el sentimiento de la libertad expresiva, del contraste, del moverse exagerado de tantos personajes, el alambicamiento del lenguaje que traduce estados cle ánimo, con intensidad y profundidad. A veces su voz adquiere sin embargo, la belleza rítmica, alegre y naturalista y los personajes se mueven dentro del lento desplazarse del burgo como en Las Alegres Comadres de Windsor; o en la Comedia de las Equivocaciones, donde la rigurosa trama procede del latino Plauto. Detiene el tumulto de las tempestades que agitan el corazón del hombre y habla con la sencillez calmada de la provincia o en la equilibrada sátira que fuera maestro Horacio. A un campo mayormente renacentista, armonioso y lógico responden El Sueño de una Noche 
de Verano y El Mercader de Venecia. La primera fue compuesta como entretenimiento para unas fiestas nupciales en 1590. La tradición clásica fluye en esta comedia a través de la historia amorosa de Píramo y Tisbe; y se combina el humorismo, la ensoñación y un delicioso sentimentalismo ajustado al buen gusto del poeta. El Mercader de Venecia se compuso por los mismos años que la onterior comedia. En ella se han señalado principios morales; hay una condenación de la avaricia y usura; y la expresión -en el campo opuesto- de la inteligencia de Porcia, puesta al servicio del amor y de la amistad para lograr el triunfo sobre Shylock. Ambas piezas responden, asi, a un lado clásico de la producción Shakesperiana; y ambas son deleite de juventudes. El Teatro de los Niños de Seix Barral las adaptó para sus maravillosas versiones en juguete de la literatura universal, junto con La Fierecilla Domada.

En la Revista Letras escribi dentro de un artículo titulado "El Arte Barroco y su repercusión en la Literatura, № 26, Primer Cuatrimestre de 1943, unas apreciaciones sobre Shakespeare señalando la intensidad barroca de su obra, en la libertad expresiva y la fuerza de la pasión. Angustias, retorcimiento intelectual, movimiento tumultuoso de personajes en escena, alambicamiento del lenguaje influenciado por el "eufemismo", colocan a Shakespeare en la corriente barroca. "Intensidad y profundidad —decía- mueven el escenario de ishakespeare". Alumbrado por resplandores y ensombrecido por oscuridades siniestras, el Teatro de Shakespeare no pudo ser "ni admitido ni reproducido en" la etapa neoclásica, como lo decía también entonces; y sólo pudo renacer en la manifestación sensible $y$ en el claro-oscuro del romanticismo, como un poeta y dramaturgo para ser entendido por el siglo $X \mid X$. Esto lo ha dicho asimismo Estuardo Núñez en su libro Autores Ingleses y Norteamericanos en el Perú, publicado por el Ministerio de Educación Pública, en 1956. En él tiene un capítulo de especial importancia para recordar el singular genio de Straford: "Luces y Nieblas de Shakespeare en el Perú". Nuestro Romanticismo volvió sus ojos al dramaturgo inglés. Debemos precisar que apasionó grandemente a nuestros románticos la cultura anglosajona $y$ ya lo dijo Palma, en cita que recoge también Núñez: "Traduclamos con infinito trabajo a Shakespeare y Byron". Luego el aludido crítico nos mostrará los poemas de Federico Flores Galindo (Dalmiro) y 
Modesto Molina, aparecidos en El Correo del Perú y que giran en torno al "Ser o no Ser" de Hamlet, que servirá de tema más tarde a Luis Benjamín Cisneros, a José Santos Chocano, a Enrique Bustamante y Ballivián $y$ a Manuel Beltroy, entre otros poetas. Es Hamlet, quien más impresiona a nuestros románticos; ya Ignacio Noboa traduce la escena del acto $V$; ya Nemesio Vargas hace una versión erudita de la misma pieza dramática. Felipe Sassone realiza en 1915 una tragicomedia titulada: El Intérprete de Hamlet. La sensibilidad romántica y su repercusión modernista -Bustamante y Ballivián, Beltroy, Sassone- encuentran en el contraste aludido el máximo claro-oscuro: la vida y la muerte; y para ambas corrientes la muerte resulta el supremo sortilegio, la máxima evocación. Molina: "Ser era hastio, era dolor, miseria/ desencanto, agonía, desconsuelo./ No ser era abatir a la materia,/ y abandonar el mundo por el cielo..." Y Bustamante Ballivián: "Entre el ser y el no ser/ la razón del no ser es la más fuerte".

Aparte de esa insistencia en el Hamlet, José Arnaldo Márquez, con singular maestría tradujo: Sueño de una Noche de Verano, Modida por Medida, Coriolano, Cuento de Invierno, Julio César, Como gustéis, Comedia de Equivocaciones, Las Alegres Comadres de Windsor. Pienso que nuestro Teatro Universitario podría hacer una lectura interpretativa de Julio César, en versión de Arnaldo Márquez, que signifciaría así un homenaje de especial significación peruanista.

Debemos tambiénga Estuardol Núñez elsacopio de datos en torno de las primeras presentaciones de Shakespeare en el Perú: Macbeth y El Mercacier de Venecia, según las informaciones de El Comercio de 6 y 11 de setiembre de 1865, cuatro años después que Palma se refería por primera vez a él en el artículo soibre Carlos Augusto Salaverry, aparecido en la Revista da Lima. Así como también sobre la existencia de dos Tesis Universitarias sobre Shakespeare; una de Constantino Salazar; y la otra de Luis Miró Quesada Guerra, que se publicó en la Imprenta de El Comercio en 1903.

De especial trascendencia para sentir a Shakespeare en el Perú, es que una generación, al igual que las contemporáneas de los otros países íberoamericanos, llevó el nombre de Ariel. Y que nuestro Francisco García Calderón -como también ya lo dijimos- hiciera 
de ese personaje de La Tempestad el intérprete del idealismo que surgiera alrededor del 900 como una respuesta al positivismo y a las corrientes pragmáticas anglo-sajonas. En contraste que parece shakespereano, trataba precisamente de ofrecerse a través de un personaje recogido por un autor inglés la figura icleal que nuestros escritores iberoamericanos concebian frente al mundo anglosajón. Por encima de esas posiciones ya superadas, los escritores presentes del Perú ven en Shakespeare un norte de aspiraciones intelectuales, un mar insondable de posibilidades artisticas $y$ un autor que está por encima del simple tumulto que quiso verse en él. Lo sen. timos tan suficientemente moderno que aún sigı:e trastornando la sociedad y el arte.

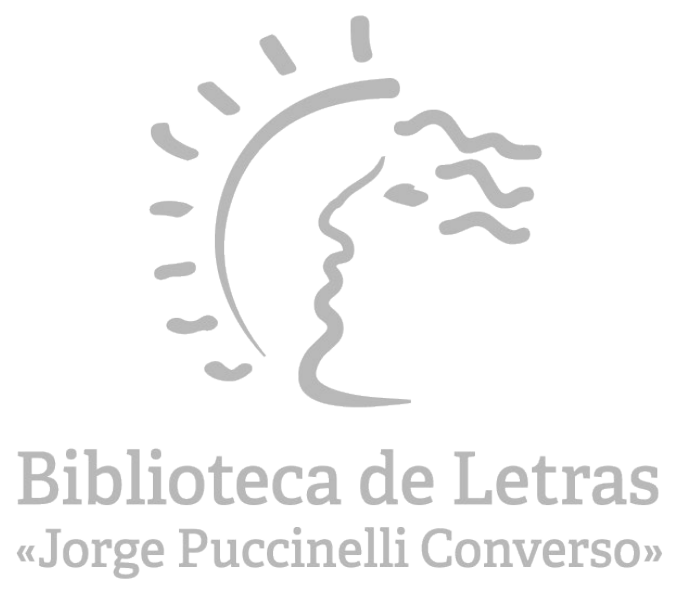

